\title{
Gridded inventories of historical usage for selected organochlorine pesticides in Gansu Province, China
}

\author{
Tao Huang • Xiangyang Li • Chongguo Tian • \\ Xianming Yang $\cdot$ Li Wang $\cdot$ Yuan Zhao $\cdot$ Jianmin Ma • \\ Hong Gao
}

Received: 30 November 2012 / Accepted: 11 February 2013

(C) Springer-Verlag Berlin Heidelberg 2013

\begin{abstract}
HCHs and DDTs were banned in 1983 in China; however, they are still remaining in various environmental media. Since endosulfan was introduced in China in 1994, it is widely used in agriculture. In this study, temporal and spatial uses of endosulfan, HCHs, and DDTs in Gansu province of China have been presented. It is estimated that the total usage is 701 tons for endosulfan between 1994 and 2007, 1,712 tons for HCHs between 1952 and 1983, and 462 tons for DDTs between 1951 and 1983, respectively. Endosulfan usage increased dramatically in 1998 due to its application on other crops except on cotton. The HCH and DDT usage displayed a rapid increase after 1972, reaching the peak in 1976 and in 1975, respectively; since then, they declined until being banned in 1983. The gridded usage inventories of these three kinds of organochlorine pesticides in Gansu province, with a $1 / 4^{\circ}$ longitude by $1 / 6^{\circ}$ latitude
\end{abstract}

Responsible editor: Philippe Garrigues

T. Huang $\cdot$ H. Gao $(\bowtie)$

Key Laboratory of Western China's Environmental

Systems (Ministry of Education), College of Earth and Environmental Sciences, Lanzhou University,

Lanzhou 730000, People's Republic China

e-mail: honggao@1zu.edu.cn

X. Li $\cdot$ X. Yang $\cdot$ L. Wang $\cdot$ Y. Zhao

College of Earth and Environmental Sciences, Lanzhou

University, Lanzhou 730000, People's Republic China

C. Tian

Key Laboratory of Coastal Zone Environmental Processes,

Yantai Institute of Coastal Zone Research (YIC),

Chinese Academy of Sciences (CAS),

Yantai 264003, China

J. Ma

Science and Technology Branch, Environment Canada,

4905 Dufferin Street, Downsview,

Toronto, Ontario M3H 5T4, Canada resolution, have been created by using different crops for endosulfan and the area of dry farmland for $\mathrm{HCHs}$ and DDTs as surrogate data. The most intensive use was in northwestern regions for endosulfan and southeastern regions for HCHs and DDTs in Gansu province.

Keywords OCPs · Gridded inventories · Gansu province

\section{Introduction}

Organochlorine pesticides (OCPs) are a common name of a group of pesticides consisting of benzene and chlorine. Some OCPs are persistent organic pollutants (POPs) that are semivolatile, bio-accumulative, persistent, and toxic (Vallack et al. 1998; Jones and de Voogt 1999). Most OCPs have been eliminated or restricted in their use in many countries because of their persistence in the environment and bioaccumulation in biota. OCPs are ubiquitous pollutants due to their long-range transport potential. They have been detected in air, seawater, ice, and mammals in the Arctic and Antarctic (Tanabe et al. 1983a, b; Iwata et al. 1993), although these pristine regions have never been primary sources of OCPs. Considering their harmful effects on man and wildlife, many international agreements are now coming into effect to reduce future environmental burdens. One recent international agreement is the Stockholm Convention on POPs, which will eliminate or at least control 12 POP substances, of which nine are OCPs (aldrin, endrin, dieldrin, heptachlor, chlordane, mires, toxaphene, DDTs, and hexachlorobenzene (HCB)) (UNEP 2001). Endosulfan, an OCP, is genotoxic in mammalian cells and generally considered to be toxic and classified by the World Health Organization and the US Environmental Protection Agency as priority pollutants and a nominator for inclusion in a future iteration of the persistent organic pollutants treaty (Jia et al. 2009). 
China started to produce and use technical $\mathrm{HCHs}$ and DDTs in 1952 and 1951, respectively. They were widely used in agriculture and were the main pesticides. The total amount of technical HCHs produced in China was 4.5 million tons before its use was banned in 1983 (Li et al. 1998), which accounted for about $30 \%$ of total world production (Wei et al. 2007). The total production of commercial DDTs was more than 0.43 milliontons from 1951 to 1983 (Wong et al. 2002). It was noted that technical HCHs and DDTs accounted for $78 \%$ of the total pesticide production and usage in China before they were banned in 1983 (Hua and Shan 1996). Moreover, 3,200 tons of lindane (almost pure $\gamma$ $\mathrm{HCH}$ ) was used between 1991 and 2000. And, DDT production also continued due to export demand and dicofol production after the restriction of technical HCHs and DDTs in 1983 (Zhang et al. 2002; Qiu et al. 2004, 2005). Due to toxicity to the health of humans and wildlife, endosulfan was included in the list of POPs in 2011. At present, the production, usage, and trade of endosulfan are banned in approximately 75 countries; however, it is still used in China. It was estimated that approximately 25,700 tons of endosulfan was used in China between 1994 and 2004, with an annual average use of 2,300 tons (Jia et al. 2009).

Within international conventions, the establishment of emission inventories for POPs is mandatory and provides the basis for further emission reductions among parties (UNEP 1999, 2001; Vestreng and Klein 2002). Furthermore, emission data and release estimates are also used by modelers, which aim to understand and predict source-receptor relationships for POPs at regional (Van Jaarsveld et al. 1997; Cohen et al. 2002) and global scales (Wania et al. 1999; Wania and Daly 2002).

By establishing gridded inventories of historical usage for POPs in a region, precision usage range for POPs can be understood, which can provide data support for the establishment of multimedia migration and conversion model, sourcereceptor relation analysis, health risk assessment, and other researches related to POPs. It is very important for policy makers to control and reduce national or regional POPs.

At present, the studies of inventories for POPs can be divided into two categories according to the scope of study. One is based on national or regional studies of inventories, and the results reflect the overall POP usage of the study area. The other one is gridded inventories by combining with GIS technology, which can more precisely reflect usage for POPs.

For national or regional studies of inventories, by collecting the data related with $\mathrm{HCHs}$, inventories of usage for $\alpha-\mathrm{HCH}, \beta-\mathrm{HCH}$, and $\gamma-\mathrm{HCH}$ from 1970 to 1996 were published in Europe. Pacyna et al. (2003) established inventories of usage for DDTs, HCB, benzo- $\alpha$-pyrene, and dioxin from 1970 to 1995 in European countries. For gridded inventories, the global spatial distribution of PCBs was established by allocating emissions by country to the
GEIA grid system $\left(1^{\circ} \times 1^{\circ}\right)$ and using population densities within each country as a surrogate parameter (Brievik et al. 2002). The global gridded inventories for $\alpha-\mathrm{HCH}$ and $\gamma$ $\mathrm{HCH}$ usage with a $1 / 4^{\circ}$ longitude by $1 / 6^{\circ}$ latitude resolution were published by using a global arable land density from EROS as surrogate data ( $\mathrm{Li}$ 1999). For the studies of Chinese gridded inventories, some OCPs such as technical HCHs and lindane ( $\mathrm{Li}$ et al. 2001), DDTs (Li et al. 1999), and endosulfan (Jia et al. 2009) were published by using a global cropland database with a $1 / 4^{\circ}$ longitude by $1 / 6^{\circ}$ latitude resolution. In addition, Zhao (2005) created inventories of historical usage for chlordane with a $1 / 4^{\circ}$ longitude by $1 / 6^{\circ}$ latitude resolution in China by using the building area of housing newly built and urban population based on prefectures as surrogate data. Dou (2006) established gridded inventories of lindane usage by allocating usage by country to a $1 / 4^{\circ}$ longitude by $1 / 6^{\circ}$ latitude gridding system and using the area of controlling wheat midge as surrogate data. Liu (2007) established inventories of historical usage for HCHs, DDTs, and lindane in the Heilongjiang River Basin of China by allocating usage by province on a $1 / 4^{\circ}$ longitude by $1 / 6^{\circ}$ latitude gridding using different gridded cropland datasets with the same resolution. Zhang et al. (2010) created gridded inventories of usage with a $1 / 4^{\circ}$ longitude by $1 / 6^{\circ}$ latitude resolution of PCBs by using the population of China as surrogate data.

The arid and semi-arid area of northwest China accounts for $20 \%$ of the total land area of China. With relatively higher altitude, this region also has very dry climate, and the annual precipitation decreased from the east to west. In northwest China, agriculture has been relatively well developed, such as irrigated agriculture in the Hexi Corridor area of Gansu province, one of the most important grain and cash crop production region. HCHs and DDTs were the most widely used pesticides in this area. While the inventories of OCPs have been studied extensively in northeastern, northern, and southeastern China, no extensive researches for inventories of OCPs in northwestern China were conducted. This study made an effort to establish gridded inventories of historical usage for selected OCPs, endosulfan, HCHs, and DDTs in Gansu province located in arid and semi-arid regions northwest of China (Fig. 1). The results of this work will provide data support for establishing OCP emission/residue inventories, health risk assessment, and other research related with OCPs in China.

\section{Materials and methods}

\section{Study framework}

In this study, we cited and improved the method for establishing gridded inventories of $\mathrm{HCH}$ usage presented 
Fig. 1 The study area for inventories of selected OCPs

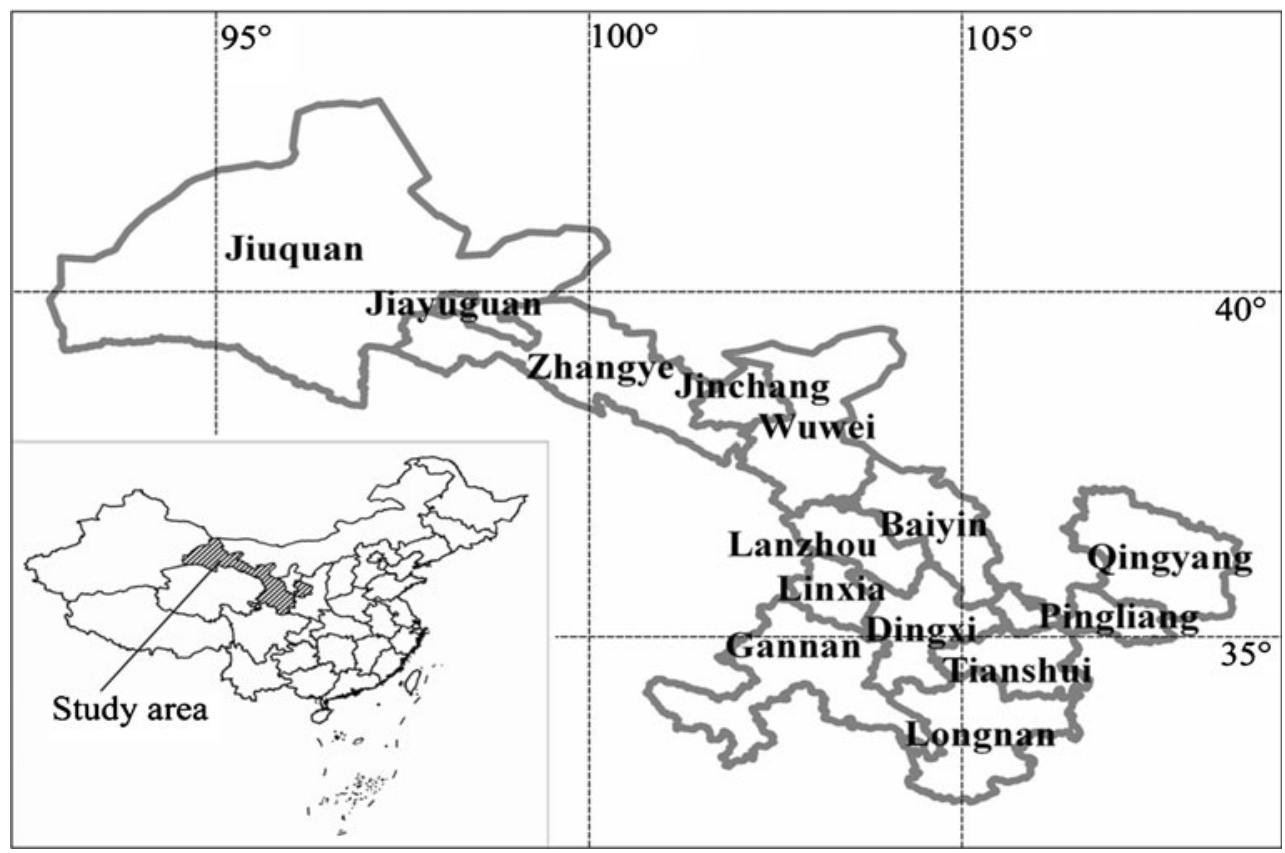

by $\mathrm{Li}$ et al. (1996) to establish the gridded inventories for historical usage for $\mathrm{HCH}$, DDT, and endosulfan in Gansu province, China (Fig. 2). Firstly, according to the usage of endosulfan on different crops per hectare, annual usage frequency, and the planting areas of those crops, we can obtain the usage of endosulfan from each prefecture. Different with endosulfan, by using the total usage of DDTs and HCHs in Gansu province and the planting areas of the crops, we can get the usage of DDTs and HCHs from each prefecture. Then, we can establish gridded inventories of usage for endosulfan, DDTs, and HCHs in Gansu province, China, by allocating the usage of pesticides of each prefecture into the grid.

Usage calculation

As an insecticide, endosulfan has been used only in agriculture in China. According to Chinese pesticides registered, endosulfan was used on six crops, e.g., cotton, tea, tobacco, wheat, apples, and pears (Pesticide Electronic Handbook 2006). There is almost no tea cultivation in Gansu province; thus, endosulfan usage on five crops, cotton, tobacco, wheat, apples, and pears, was estimated in this study.
Fig. 2 Framework to establish gridded inventories for endosulfan, $\mathrm{HCHs}$, and DDTs

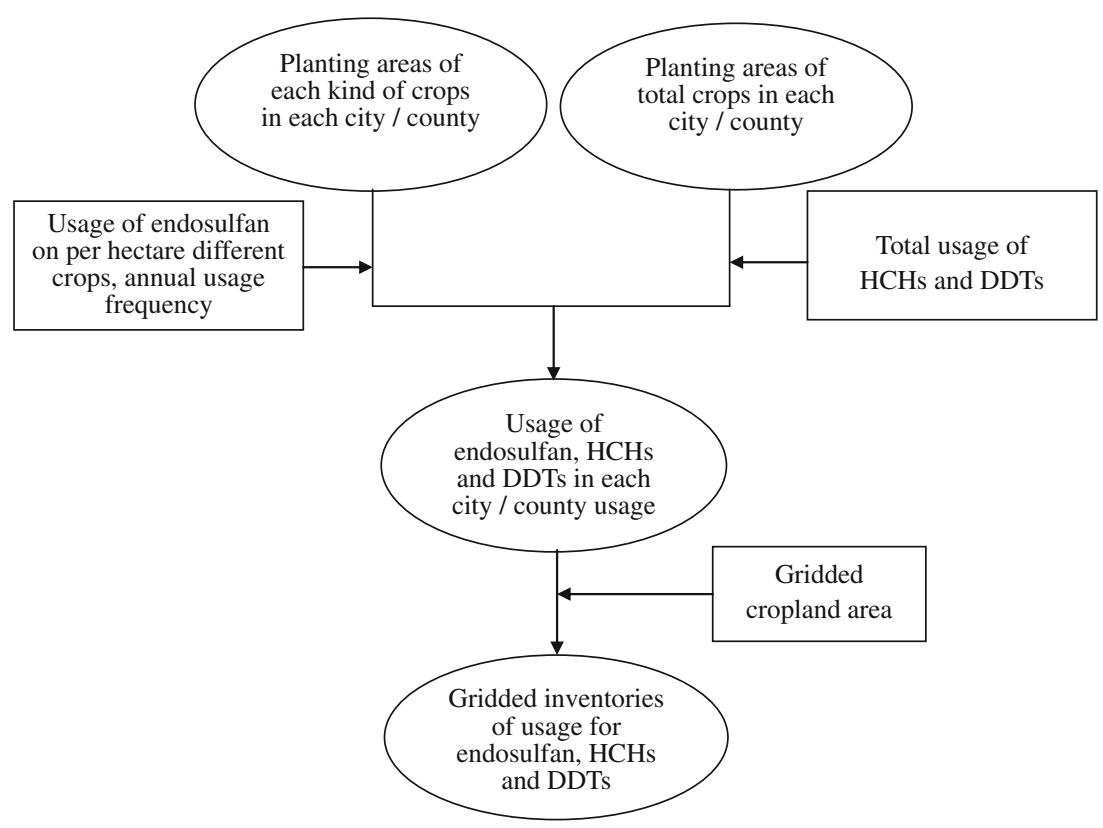


In order to estimate the use of endosulfan, the information of the average amount of endosulfan used on different crops per hectare, annual application frequencies of endosulfan on different crops, and fraction of cropland being treated by endosulfan were collected. For cotton, tobacco, wheat, and apples, the information of endosulfan usage was listed in Table 1. For pears, the annual application frequencies of endosulfan and amount used per hectare were collected from the Pesticide Electronic Handbook (2006). In addition, besides endosulfan, three other insecticides are also used on pears. By assuming that these four insecticides are equally used on pears, the fraction of cropland being treated by endosulfan is assumed to be one fourth for pears. Finally, we can collect the data of usage information of endosulfan for different crops, and these are listed in Table 1.

The usage of endosulfan can be estimated as follows:

$U_{i, t}=U_{p} S_{i, t} n_{i} k_{i}$

where $U_{i j}$ is the total usage of endosulfan on crop $i$ in year $t, U_{p}$ is the amount used per hectare for different crops, $S_{i j}$ is the area of cropland of crop $i$ in year $t, n_{i}$ is the annual application frequency of endosulfan on crop $i$, and $k_{i}$ is the fraction of the cropland $i$ that is treated by endosulfan.

The usage of DDT and $\mathrm{HCH}$ can be estimated as follows:

$U_{i, j, t}=\frac{S_{i, j, t}}{\sum_{j=1}^{n} S_{i, j, t}} U_{i, t}$

where $U_{i, j, t}$ is the total usage of pesticide $i$ in prefecture $j$ in year $t, S_{i, j, t}$ is the area of cropland treated by pesticide $i$ in prefecture $j$ in year $t$, and $U_{i, t}$ is the total usage of pesticide $i$ in Gansu province in year $t$.

\section{Usage gridding}

The purpose of usage gridding is to allocate the use of pesticides to the areas where pesticides actually are used. One OCP could be used in a large amount in some areas, but little or none in others. Accurate allocation of the use of pesticides is very important for policy makers to reduce OCPs.

In order to distribute pesticide usage database on prefecture to grid, the key is to collect the surrogate data. In this study, by using the similar method that has been applied to grid the use of pesticide ( $\mathrm{Li}$ et al. 1999; 2000), gridded cropland datasets with $1 / 6^{\circ}$ latitude by $1 / 4^{\circ}$ longitude resolution for Gansu province were created to establish gridded inventories of usage for OCPs in Gansu province, China. The gridded land includes six types: gobi, desert, dry farmland, wetland, woodland, meadowland, and water area. In Gansu province, the pesticide was mainly used on cropland including a large number of dry farmland and rare wetland. Thus, in this study, gridded inventories of historical usage for selected OCPs in Gansu province are established by choosing dry farmland data from gridded land datasets with $1 / 6^{\circ}$ latitude by $1 / 4^{\circ}$ longitude resolution as surrogate data.

\section{Results and discussions}

Temporal use trend

The total use of endosulfan between 1994 and 2007 is estimated at 701 tons, and annual average use is about 50 tons. Annual endosulfan usage from 1994 to 2007 in Gansu province is shown in Fig. 3, and it shows endosulfan usage dramatically increased in 1998, which is because all of the endosulfan was used on cotton from 1994 to 1998, and annual average usage is about 5 tons. From 1998, endosulfan was used on wheat, tobacco, apples, and other fruits, which resulted in a significant increase in endosulfan usage in 1998. From 1998 to 2007, the change of annual endosulfan usage displayed a relatively stable trend.

The total uses of HCHs between 1952 and 1983, and DDTs between 1951 and 1983, are estimated at 56,486 and 15,236 tons, and annual average use is about 1,712 and 462 tons, respectively. Figure 3 shows that annual $\mathrm{HCH}$ and DDT usage displayed three parabolic change trends

Table 1 Annual application frequencies of endosulfan, amount used per hectare of different crops, and fraction of cropland being treated by endosulfan in China (Jia et al. 2009; Pesticide Electronic Handbook 2006)

\begin{tabular}{|c|c|c|c|c|c|}
\hline \multirow[t]{2}{*}{ Crop } & \multirow[t]{2}{*}{ Application frequencies $(n)$} & \multicolumn{3}{|c|}{ Amount used per hectare of different crops ( $\mathrm{g} / \mathrm{ha}$ ) } & \multirow{2}{*}{$\begin{array}{l}\text { Fraction of cropland being } \\
\text { treated by endosulfan }(k)\end{array}$} \\
\hline & & Minimum & Maximum & Mean $\left(U_{p}\right)$ & \\
\hline Cotton & 3 & 25 & 870 & 365.5 & $1 / 4$ \\
\hline Wheat & 1 & 60 & 120 & 90 & $1 / 4$ \\
\hline Apples & 3 & 75 & 438 & 170 & $1 / 4$ \\
\hline Pears & 4 & 125 & 438 & 147 & $1 / 8$ \\
\hline Tobacco & 2 & 87.5 & 525 & 350 & $1 / 4$ \\
\hline
\end{tabular}


Fig. 3 Annual endosulfan, $\mathrm{HCH}$, and DDT, usage

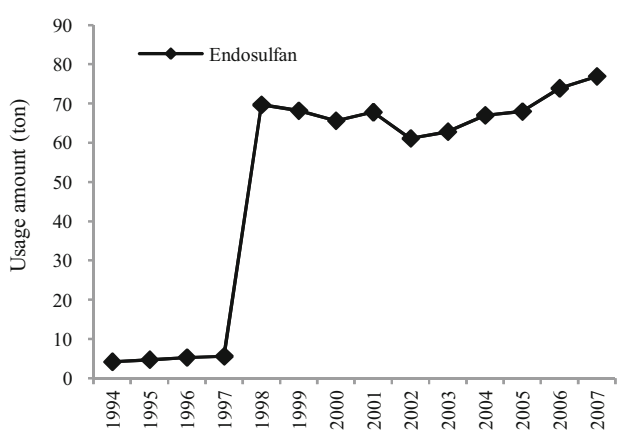

(1951-1962, 1963-1968, 1969-1983). Compared with the first two stages, $\mathrm{HCH}$ usage increased and DDT usage decreased in the third stage. The $\mathrm{HCHs}$ and DDTs reached the peaks of 3,281 tons in 1976 and 758 tons in 1975, respectively, in the third stage; since then, they displayed a decline until they were banned in 1983.

The annual endosulfan usage on different crops is given in Fig. 4. The endosulfan usage on pears and tobacco has no obvious change from 1998 to 2007. The endosulfan usage on cotton increased from 1994 to 2007, especially after 2002. For apples, the endosulfan usage decreased from 1998 to 2002 and increased after 2002, which is due to the change of the apple planting area. The apple area decreased from 199.97 thousandha in 1998 to 163.53 thousandha in 2002, and since then, it increased to 247.64 thousandha in 2007 in Gansu province. For wheat, the cultivation area decreased from 1,330.16 thousand ha in 1998 to 924.14 thousandha in 2007, which resulted in the decrease of endosulfan usage on wheat from 29.62 tons in 1998 to 20.67 tons in 2007.

Figure 5 gives the total endosulfan usage on different crops. It shows that most of the endosulfan was applied to wheat and apples, which reached 283.13 and 237.24 tons between 1998 and 2007, respectively, and accounted for $67.8 \%$ of the total endosulfan usage, followed by cotton (156.79 tons), pears (5.53 tons), and tobacco (4.49 tons).

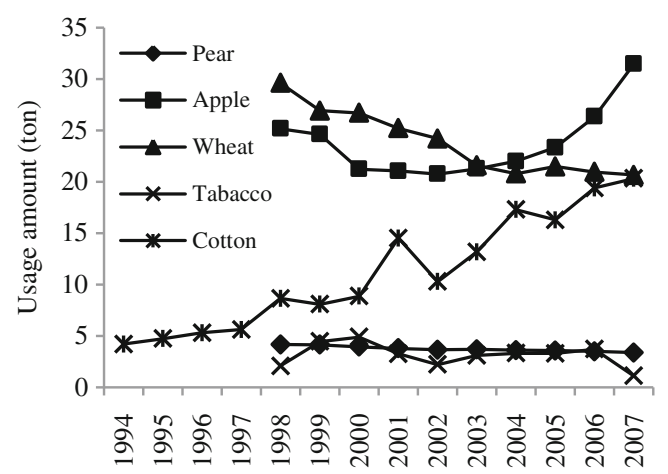

Fig. 4 Annual endosulfan usage on different crops
Usage based on prefectures

Figure 6 depicts selected OCP usage based on prefectures, and it shows that the prefecture with the highest usage of endosulfan was Dunhuang with large-scale cotton cultivation, followed by Tianshui, Jinta, Zhenyuan, and Qinan with a large number of wheat and apples. HCH and DDT usage were mainly distributed in areas with developed agriculture. $\mathrm{HCH}$ usage is mainly concentrated in Hunning, Dingxi, Zhenyuan, Tianshui, and Jingning, and DDT usage is mainly concentrated in Hunning, Dingxi, Jingning, Tianshui, and Zhenyuan. Table 2 listed the top ten prefectures with the highest usage of endosulfan, $\mathrm{HCH}$, and DDTs, respectively. According to our estimation, total endosulfan usage of the top ten prefectures between 1994 and 2007 is 373 tons, $39 \%$ of total usage of 79 prefectures in Gansu province. The total HCH usage between 1952 and 1983 and DDT usage between 1951 and 1983 of the top ten prefectures is 20,030 and 6,831 tons, which accounted for 31 and $35 \%$ of the total usage of 79 prefectures in Gansu province.

\section{Gridded usage}

The selected OCP usage based on prefectures in Gansu province is the average use amount. However, one OCP could be used in a large amount in some agricultural regions and little or none in other regions, such as

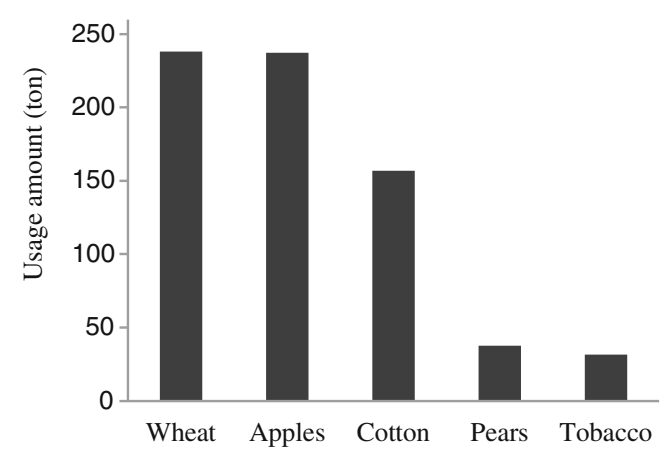

Fig. 5 Total endosulfan usage on different crops 

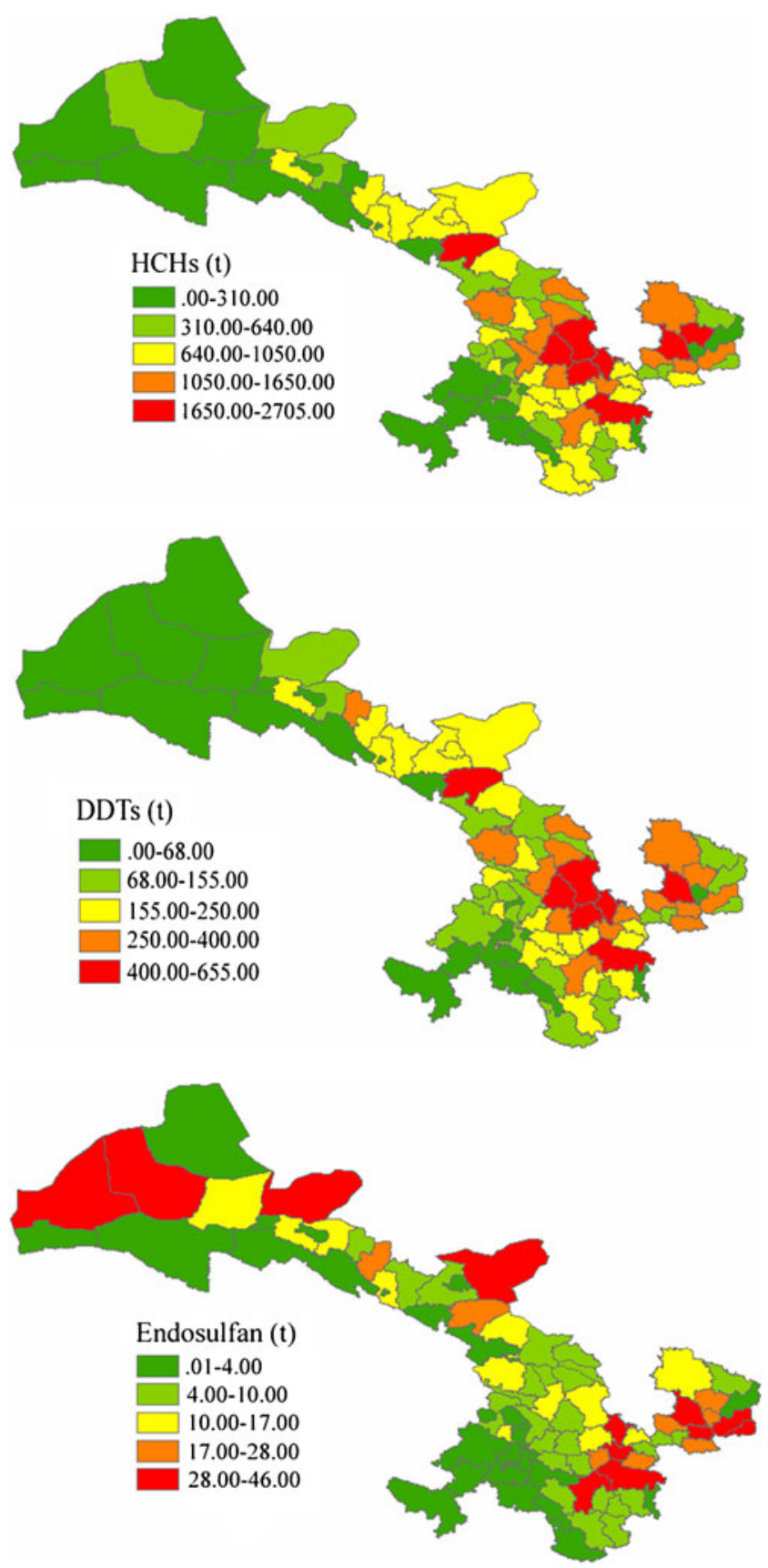

Fig. 6 Distribution of OCP usage based on prefectures

desert and gobi regions, which is very essential for policy makers.

Distribution of annual endosulfan usage was calculated on cotton from 1994 to 2007 and on wheat, apples, pears, and tobacco from 1998 to 2004 in China, and annual HCH usage from 1952 to 1983 and DDT usage from 1951 to 1983 were calculated according to area of dry farmland with a $1 / 4^{\circ}$ longitude by $1 / 6^{\circ}$ latitude resolution, and the results were given in Fig. 7. It shows that the most intensive use of endosulfan, HCHs, and DDTs was in northwestern and
Table 2 Top ten prefectures with the highest use of selected OCPs in Gansu province

\begin{tabular}{|c|c|c|c|c|c|c|}
\hline \multirow[t]{2}{*}{ Rank } & \multicolumn{2}{|c|}{ Endosulfan (ton) } & \multicolumn{2}{|l|}{ HCHs (ton) } & \multicolumn{2}{|l|}{ DDTs (ton) } \\
\hline & 1994-2007 & & $195-1983$ & & $1951-1983$ & \\
\hline 1 & Dunhuang & 45.1 & Huining & $2,701.4$ & Huining & 652.1 \\
\hline 2 & Tianshui & 41.0 & Dingxi & $2,421.3$ & Dingxi & 588.0 \\
\hline 3 & Jinta & 40.1 & Zhenyuan & $2,268.3$ & Jingning & 554.7 \\
\hline 4 & Zhenyuan & 37.7 & Tianshui & $2,065.6$ & Tianshui & 501.2 \\
\hline 5 & Qinan & 37.0 & Jingning & $2,036.9$ & Zhenyuan & 496.0 \\
\hline 6 & Minqing & 35.9 & Tongwei & $1,957.2$ & Qinan & 470.0 \\
\hline 7 & Jingning & 34.2 & Wuwei & $1,856.9$ & Tongwei & 443.9 \\
\hline 8 & Jinchuan & 34.1 & Qingyang & $1,652.1$ & Wuwei & 394.9 \\
\hline 9 & Anxi & 34.0 & Ning & $1,554.5$ & Qingyang & 373.3 \\
\hline 10 & $\mathrm{Li}$ & 39.8 & Qinan & $1,515.7$ & Ning & 367.1 \\
\hline
\end{tabular}

southeastern regions of Gansu province, which is due to developed agriculture in these regions. Figure 4 shows that endosulfan is mainly applied to wheat, apples, and cotton. In China, DDT was mainly used in agriculture for controlling armyworms, ball worm, pink ball worms, apple tortrix moths, and greenish brown hawk moths on wheat, maize, cotton, orchard, soybean, and sorghum (Cai et al. 1992). Crops on which $\mathrm{HCH}$ was widely used in China were rice, wheat, maize, cotton, soybean, sorghum, orchards, and some vegetables to attack a wide variety of pests for different crops (Wei et al. 2007). In Gansu province, wheat and apples were mainly distributed in the southeastern and Hexi corridor regions, and cotton was mainly concentrated in the northwestern region. In addition, a large area of desert and gobi existed in Gansu province, of which above $90 \%$ are in the northwestern area. In addition, in the southwestern region, which plants crops, animal husbandry is the main economic pillar, and an extensive pasture is distributed in this region. Thus, OCPs were rarely used in the desert, gobi in the northwestern region, and pasture in the southwestern region.

\section{Uncertainty}

Uncertainty analysis for usage data is an important part of any inventory. It can clearly understand the limitations and deficiencies of the usage inventory, which can provide a basis for estimating the factors that lead to errors in the establishment of the inventory. Many factors could create uncertainties for these gridded usage inventories. For example, the regional and time differences were neglected in this study. Because they span a relatively large latitude range in Gansu province, natural conditions are very different for different regions, such as temperature and precipitation, which result in differences of pest situation for the same 


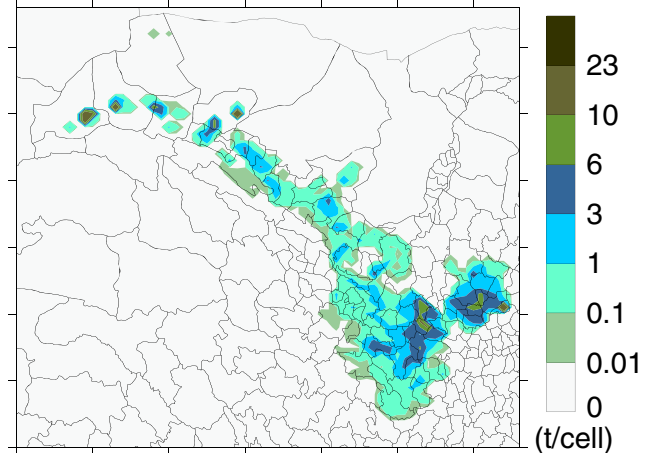

(a)Endosulfan

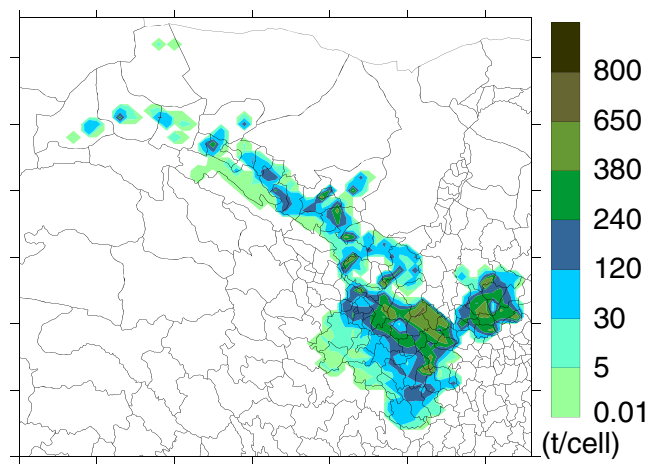

(b) $\mathrm{HCHs}$

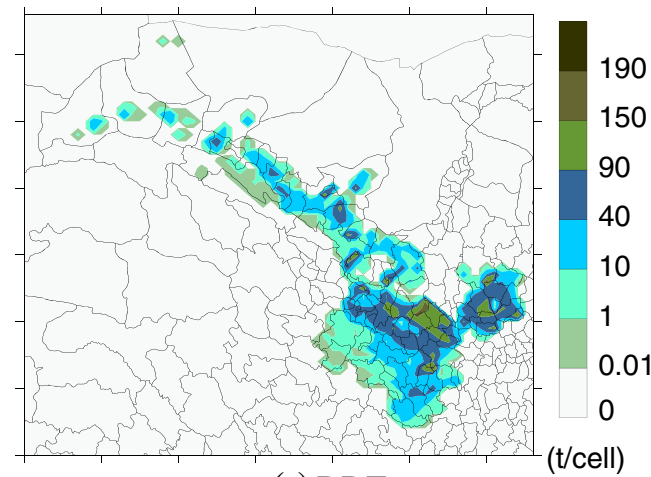

(c) DDTs

Fig. 7 Distribution of OCPs with a $1 / 4^{\circ}$ longitude by $1 / 6^{\circ}$ latitude resolution

crop in the different regions. Thus, for endosulfan, annual application frequencies and amount used for the same crop are different in the different regions. The application rate of endosulfan on the same crop could differ from year to year or season to season. In addition, the surrogate data that we used could be the sources for uncertainties in allocation of the usage. Ideally, statistical estimates of uncertainty would be provided for each province or grid cell. To make such estimates in this work is very difficult. In addition, except for dry farmland, the crops were also planted in a small number of other types of land in the grid with a $1 / 4^{\circ}$ longitude by $1 / 6^{\circ}$ latitude resolution. The dry farmland with grid was selected as surrogate data to calculate the gridded inventories usage for endosulfan, $\mathrm{HCHs}$, and DDTs, which also lead to the uncertainty of usage inventories.

\section{Conclusions}

Based on the total areas of major crops on which endosulfan was applied, the average application rates on individual crops, the fractions of the croplands that were treated by endosulfan, and the area of dry farmland treated with $\mathrm{HCHs}$ and DDTs, the temporal variation, spatial distribution of endosulfan usage from 1994 to 2007, $\mathrm{HCH}$ usage from 1952 to 1983 , and DDT usage from 1951 to 1983 were generated at prefecture levels, as well as on a $1 / 4^{\circ}$ longitude by $1 / 6^{\circ}$ latitude gridding system.

The present study shows that, in Gansu province of China, the endosulfan between 1994 and 2007, HCHs between 1952 and 1983, and DDTs between 1951 and 1983 were approximately $701,56,486$, and 15,236 tons, and annual average use was $50,1,712$, and 462 tons, respectively. Endosulfan usage increased dramatically in 1998 due to application on other crops in 1998 except on cotton. The HCH and DDT usage displayed a rapid increase after 1972, reaching the peak in 1976 and in 1975, respectively; since then they declined until they were banned in 1983. For spatial distribution, the most intensive use of endosulfan, HCHs, and DDTs was in the northwestern and southeastern regions of Gansu province.

The inventories of gridded usage of endosulfan, $\mathrm{HCHs}$, and DDTs in Gansu province of China with a $1 / 4^{\circ}$ longitude by $1 / 6^{\circ}$ latitude resolution will be used in creating the emission and residue inventories in the near future. This effort is especially important to understand POP usage information and reduce them for policy makers.

Acknowledgments This research was financially supported by the National Natural Science Foundation of China (no. 40971267); "Chun Hui Project," an International Cooperation Project in Scientific Research (no. Z2008-1-62025); and the Excellence Funding Program of Overseas Visiting Scholar in the Gansu Provincial Science and Technology Activity.

\section{References}

Brievik K, Sweetman A, Pacyna JM (2002) Towards a global historical emission inventory for selected PCB congeners a mass balance approach. 1. Global production and consumption. Sci Total Environ 290:181-198

Cai DJ, Sun LJ, Ke JL, Tang GC (1992) Technical report RP032: pesticide usage in China. Environment Canada, Ontario 
Cohen MD et al (2002) Modeling the atmospheric transport and deposition of PCDD/F to the Great Lakes. Environ Sci Technol 36:4831-4845

Dou YW (2006) Griddied usage inventories of lindan in China, environmental fate and health risk assessment of indan in individual area in China. Master's dissertation, Beijing University, Beijing

Hua XM, Shan ZJ (1996) The production and application of pesticides and factor analysis of their pollution in environment in China. Adv Environ Sci 4:33-45

Iwata H, Tanabe S, Sakal N, Tatsukawa R (1993) Distribution of persistent organochlorines in the oceanic air and surface seawater and the role of ocean in their global transport and fate. Environ Sci Technol 27:1080-2098

Jia HL, Li YF, Wang DB (2009) Endosulfan in China 1-gridded usage inventories. Environ Sci Pollut Res 16:295-301

Jones KC, de Voogt P (1999) Persistent organic pollutants (POPs): state of the science. Environ Pollut 100:209-221

Li YF (1999) Global gridded technical hexachlorocyclohexane usage inventories using a global cropland as a surrogate. J Geophys Res 104:23785-23797

Li YF, McMillan A, Scholtz MT (1996) Global HCH usage with $1^{\circ} \times 1^{\circ}$ longitude/latitude resolution. Environ Sci Technol 30:3525-3533

Li YF, Cai DJ, Singh A (1998) Hexachlorocyclohexane use trends in China and their impact on the environment. Arch Environ Contamin Toxicol 35:688-697

Li YF, Cai DJ, Singh A (1999) Historical DDT use trend in China and usage data gridding with $1 / 4$ by $1 / 6$ longitude/latitude resolution. Adv Environ Res 2:497-506

Li YF, Scholtz MT, van Heyst BJ (2000) Global gridded emission inventories of a-hexachlorocyclohexane. J Geophys Res 105:6621-6632

Li YF, Cai DJ, Shan ZJ (2001) Gridded usage inventories of technical hexachlorocyclohexane and lindane for China with $1 / 6^{\circ}$ latitude by $1 /$ $4^{\circ}$ longitude resolution. Arch Environ Contam Toxicol 41:261-266

Liu LY (2007) Pollution in surface soil of HCHs and DDTs in Heilongjiang River Basin, China. Doctor's dissertation, Harbin Institute of Technology, Harbin

Pacyna MJ, Breivik K, Münch J, Fudala J (2003) European atmospheric emissions of selected persistent organic pollutants, 1970-1995. Atmos Environ 37:119-131

Pesticide Electronic Handbook (2006) http://www.chinapesticide.gov.cn

Qiu XH, Zhu JL, Pan HS (2004) Organochlorine pesticides in the air around the Taihu Lake. China Environ Sci Technol 38:1368-1374

Qiu XG, Zhu T, Yao B, Hu JX, Hu SW (2005) Contribution of dicofol to the current DDT pollution in China. Environ Sci Technol 39:43854390
Tanabe S, Hikada H, Tatsukawa R (1983a) PCBs and chlorinated hydrocarbon pesticides in the Antarctic atmosphere and hydrosphere. Chemosphere 1:277-288

Tanabe S, Mori T, Tatsukawa R (1983b) Global pollution of marine mammals by PCBs, DDTs and HCHs (BHCs). Chemosphere $12: 1269-1275$

UNEP (1999) Dioxin and furan inventories: national and regional emissions of PCDD/F. Prepared by UNEP Chemicals. United Nations Environment Programme. Geneva, Switzerland, 100 pp. http://www.chem.unep.ch/pops/pdf/dioxinfuran/difurpt.pdf

UNEP (2001) The Stockholm convention on persistent organic pollutants. United Nations Environmental Programme. http:// www.pops.int/documents/convtext/convtext_en.pdf

Vallack HW, Bakker DJ, Brandt I (1998) Controlling persistent organic pollutants-what next? Environ Toxicol Pharma $6: 143-175$

Van Jaarsveld JA, Van Pul WAJ, De Leeuw FA (1997) Modeling transport and deposition of persistent organic pollutants in the European region. Atmos Environ 31:1011-1024

Vestreng V, Klein H (2002) Emission data reported to UNECE/EMEP: quality assurance and trend analysis \& presentation of WebDab. MSC-W Status Report 2002. EMEP-MSC-WNote 1/2002. Meteorological Synthesizing Centre-West. Oslo, Norway

Wania F, Daly GL (2002) Estimating the contribution of degradation in air and deposition to the deep sea to the global loss of PCBs. Atmos Environ 36:5581-5593

Wania F, Mackay D, Li YF, Bidleman TF, Strand A (1999) Global chemical fate of alpha-hexachlorocyclohexane. 1. Evaluation of a global distribution model. Environ Toxicol Chem 18:1390 1399

Wei DB, Kameya T, Urano K (2007) Environmental management of pesticidal POPs in China: past, present and future. Environ Int 33:894-902

Wong MH, Choi K, Grosheva E, Sakai S, Shibata Y, Suzuki N,Wang J, Zhou H, Leung A (2002) Central and North East Asia regional report-regionally based assessment of persistent toxic substances. UNEP/GEF.

Zhang G, Andrew H, Alan H, Mai BX (2002) Sendimentary records of DDT and HCH in the Pearl River Delta. South China Environ Sci Technol 36:3671-3677

Zhang Z, Tian CG, Jia HL, Li YF (2010) Gridded Chinese polychlorinated biphenyls (PCBs) usage inventories. J Nat Sci Heilongjiang Univ 27:111-116

Zhao LJ (2006) Usage inventories of chlordane and DDT in China. Master's dissertation, Beijing University 